\title{
Cardiovascular Disease Burden in Patients with Non-Dialysis Dependent Chronic Kidney Disease in Cameroon: Case of the Douala General Hospital
}

\author{
Marie Patrice Halle1,2, Mogo Franklin Kom³, Felicite Kamdem,2, Sidick Mouliom, \\ Hermine Fouda ${ }^{2,4}$, Anasthase Dzudie ${ }^{2,4}$, Folefack Francois Kaze ${ }^{4}$, Enow Gloria Ashuntantang4 \\ ${ }^{1}$ Department of Clinical Sciences, Faculty of Medicine and Pharmaceutical Sciences, University of Douala, Douala, Cameroon \\ ${ }^{2}$ Department of Internal Medicine, Douala General Hospital, Douala, Cameroon \\ ${ }^{3}$ Faculty of Health Sciences, University of Buea, Buea, Cameroon \\ ${ }^{4}$ Department of Internal Medicine and Specialties, Faculty of Medicine and Biomedical Sciences, University of Yaoundé 1, \\ Yaoundé, Cameroon \\ Email: patricehalle@yahoo.fr, komfranklin@yahoo.com,kamdem_djimegne@yahoo.fr, masidickyahoo.fr, \\ aitdzudie@yahoo.com,f_kaze@yahoo.fr,maglo09@hotmail.com
}

How to cite this paper: Halle, M.P., Kom, M.F., Kamdem, F., Mouliom, S., Fouda, H., Dzudie, A., Kaze, F.F. and Ashuntantang, E.G. (2020) Cardiovascular Disease Burden in Patients with Non-Dialysis Dependent Chronic Kidney Disease in Cameroon: Case of the Douala General Hospital. Open Journal of Nephrology, 10, 171-186. https://doi.org/10.4236/ojneph.2020.103017

Received: June 3, 2020

Accepted: July 4, 2020

Published: July 7, 2020

Copyright (๑) 2020 by author(s) and Scientific Research Publishing Inc. This work is licensed under the Creative Commons Attribution International License (CC BY 4.0).

http://creativecommons.org/licenses/by/4.0/ (c) (i) Open Access

\begin{abstract}
Introduction: Cardiovascular disease (CVD) is the major cause of morbidity and mortality in patients with chronic kidney disease (CKD). Objective: To evaluate the burden of CVD and audit the management of cardiovascular risk factors (CVRF) in patients with non-dialysis (ND) dependent CKD in Cameroon. Patients and Methods: A cross-sectional study in the Douala general hospital was conducted from January to March 2016, including CKD patients' stages 3 - $5 \mathrm{ND}$. Socio-demographic data, comorbidities, medications and biological data were extracted from patient's records. For each participant, lipid profile and urinary protein excretion were measured; a resting electrocardiogram was done. Hypertension, diabetes, dyslipidemia, obesity, smoking, alcohol consumption, anemia, hyperuricemia, proteinuria and high calcium-phosphorus product were considered as CVRF. CVD was defined as a history of stroke, peripheral artery disease, coronary heart disease (CHD), left ventricular hypertrophy (LVH), heart failure (HF) and arrhythmia. We used KDOQI 2003, KDIGO 2012 and JNC 8 guidelines for definition and evaluation of the management of lipid abnormalities, proteinuria and hypertension respectively. Results: A total of 83 patients ( 45 males) were included; mean age was $56 \pm 15$ years. Mean number of CVRFs per patient was $5.19 \pm$ 1.64; hypertension (90.3\%), obesity (79.5\%), anemia (78.3\%), dyslipidemia (69.8\%) and hyperuricemia (69.8\%) were the most frequent. Mean number of
\end{abstract}


CVD per patient was $1.5 \pm 0.63$ with an overall prevalence of $69.8 \%$; LVH (48.2\%) and CHD (30.1\%), were the most frequent and prevalence increased significantly with CKD stage. Treatment rate of hypertension was $100 \%$, 53.4\% for dyslipidemia and $75.3 \%$ for anemia. Target values were achieved in $50 \%$ of participants for LDL-cholesterol and phosphorus levels, $26.6 \%$ for blood pressure and $6 \%$ for hemoglobin levels. Conclusion: CVRF are highly prevalent in non-dialyzed CKD populations in this setting. This may contribute to the burden of CVD implying strict control of these factors.

\section{Keywords}

Cardiovascular Disease, Risk Factors, Chronic Kidney Disease, Cameroon

\section{Introduction [1]}

Chronic kidney disease (CKD) is a public health problem with a prevalence estimated at $13 \%$ [1]. It progresses through 5 stages and carries a high morbi-mortality [2]. Cardiovascular disease (CVD) is frequent at each stage of CKD with reported prevalence ranging from $26 \%$ to $48 \%$ [3]-[8]. Furthermore CKD is an independent risk factor of cardiovascular morbidity and mortality [9] [10] and CVD represent almost 50\% of the causes of death in CKD patients [11] [13].

Traditional risk factors such as diabetes, hypertension, age, gender, and dyslipidemia are the main cardiovascular risk factors (CVRF) in general, but in CKD patients, specific factors such as anemia, endothelial dysfunction, vascular calcification, hyperparathyroidism, hyperhomocysteinemia, albuminuria, and chronic inflammation are associated with CVD. Studies have shown that more than one CVRF existed in patients with CKD, and the number increased with decreasing renal function [13] [14]. Majority of these CVRF are potentially modifiable. Early detection and adequate management of these factors is a key strategy in the prevention of CVD. Blood pressure should be maintained below 140/90 $\mathrm{mmHg}$ and blockage of the renin-angiotensin-aldosterone system (RAAS) is the corner stone of the treatment [15] [16]. In diabetic patients hemoglobin A1C levels below 7\% and treatment of dyslipidemia with low-density lipoprotein cholesterol below $90 \mathrm{mg} / \mathrm{dl}$ is fundamental [17] [18] [19]. Anemia a strong predictor of left ventricular hypertrophy should be treated with recommended hemoglobin levels between 11 and $12 \mathrm{~g} / \mathrm{dl}$ [20] [21] [22]. Treatment of hypophosphatemia reduces the rate of cardiac valve calcification and CKD progression [23] [24]. Studies have shown that treatment of these risk factors is suboptimal and the control poor [25].

CKD is a major health issue in sub-Saharan Africa (SSA) with an estimated prevalence of $13.9 \%$ [26]. Morbi mortality of these patients is high due to the appearance of CVD [3]. The epidemiology of CVRF and CVD in CKD patients in SSA is limited. Few studies reported that the burden of CVRF and CVD is high in CKD patients in this setting and the care of these patients is largely in- 
adequate and suboptimal [27] [28]. In Cameroon, CKD prevalence is high mainly due to hypertension, diabetes and chronic glomerulonephritis [29] [30]. Patients carry a high morbi-mortality, late referral to nephrologist as well as poor management is frequent [31] [32] [33], and there is no data on the epidemiology of CVRF and CVD in these patients. Therefore, we undertook this study aiming to describe the spectrum of CVRF and evaluate their management according to guidelines among CKD patients in Cameroon.

\section{Patients and Methods}

\subsection{Study Design and Setting}

This cross sectional study was carried out from 1st January to 31st March 2016 in the outpatient section of the nephrology unit in Douala General Hospital (DGH), a tertiary referral hospital in Cameroon. DGH is a 320 bedded public institution and the main referral hospital for patients with kidney disease in the littoral region of the country. The medical staff of the unit comprises two nephrologists, one general practitioner. Patients with CKD referred to the unit are assigned a unique identifier and attached to one of the nephrologists, and then followed-up at intervals that are determined by the stage of the renal disease and comorbidities. At the first consultation in the unit, each patient has clinical assessment and laboratory tests done. The diagnosis of kidney disease was based on elevated serum creatinine level with or without urine dipstick abnormalities, and glomerular filtration rate (GFR) less than $60 \mathrm{ml} / \mathrm{min} / 1.73 \mathrm{~m}^{2}$. GFR was estimated using the CKD EPI equation [34]. The etiology of CKD was mostly based on clinical arguments in the absence of renal biopsy.

\subsection{Data Collection}

Final year undergraduate medical students collected consecutively data of all patients who provided a written informed consent and attended their first nephrology consultation with a nephrologist diagnosis of CKD stage 3 to 5 non-dialysed. We included all consenting patients with CKD stage 3 to 5 non-dialyzed and followed up in the unit for more than 3 months. From medical records, we collected relevant data: socio-demographic (sex, age, level of education, source of funding), anthropometric parameters (weight, height, waist and hip circumference), comorbidities (hypertension, diabetes mellitus, history of CVD, HIV, Gout), lifestyle habit (alcohol and tobacco use), etiology of CKD, medications and blood pressure at referral were recorded. Biological parameters done within 3 months of inclusion in the study (serum urea and creatinine level, glycaemia, uric acid, hemoglobin level, serum albumin, calcium, and phosphorus) were collected. For each participant $5 \mathrm{ml}$ of fasting blood was collected for triglycerides, total cholesterol (TC), high density lipoprotein cholesterol (HDL-C), low density lipoprotein cholesterol (LDL-C) measurement using AUTOMATIC COBAS 311 (HITACHI', TOKYO.105-8717 JAPAN) in the biochemical laboratory of the DGH. Also a spot urine sample was collected be- 
fore 9.am for protein and creatinine dosage by the pyrogallol red calorimetric method and the Jaffe kinetic method respectively, using the visual spectrophotometer (BIOMERIEUX, FRANCE). The urinary protein to creatinine ratio (UPCR) was computed as urinary protein/urinary creatinine in $\mathrm{mg} / \mathrm{g}$. A resting electrocardiogram (ECG) was done for all participants using a single channel CARDIART 6180T ECG (2011 FROST and SULLIVAN-Delhi-India). The ECG leads were placed accordingly, in line with the recommendation of the American Heart Association guidelines [35].

\subsection{Definitions and Calculations}

Chronic kidney disease was defined as estimated GFR $<60 \mathrm{ml} / \mathrm{min}$ for more the 3 months associated with or without complications such anemia, hypocalcaemia, hyperphosphatemia, and other signs of chronicity such as abnormalities of kidney size or structure on ultrasound.

CKD was classified using the KDIGO classification as followed: Stage 3a: eGFR $=45-59 \mathrm{ml} / \mathrm{min} / 1.73 \mathrm{~m}^{2}$, Stage $3 \mathrm{~b}$ : eGFR $30-44 \mathrm{ml} / \mathrm{min} / 1.73 \mathrm{~m}^{2}$, Stage 4 : eGFR 15 - $29 \mathrm{ml} / \mathrm{min} / 1.73 \mathrm{~m}^{2}$, Stage 5: eGFR < $15 \mathrm{ml} / \mathrm{min} / 1.73 \mathrm{~m}^{2}$ [15].

Hypertension, diabetes, dyslipidemia, obesity, smoking and alcohol use were considered as traditional CVRF. Hypertension was defined as either blood pressure $>140 / 90 \mathrm{mmHg}$, or use of antihypertensive medications. Diabetes mellitus was defined as either a history of diabetes, or fasting glucose $\geqq 7.0 \mathrm{mmol} / \mathrm{L}$, or $\mathrm{HbAlc} \geqq 7 \%$, or use anti-diabetic medications. Dyslipidemia was defined as any abnormality of plasma lipid concentration or treatment with statin. Lipid abnormalities were considered as; Total cholesterol $>2.40 \mathrm{~g}$, LDL $>1.60 \mathrm{~g} / \mathrm{l}$, $\mathrm{HDL}<0.40 \mathrm{~g} / \mathrm{l}$, Triglyceride $>2 \mathrm{~g} / \mathrm{l}[36]$.

BMI was calculated using the formula [Weight $\left./(\text { Height })^{2}\right]$. Obesity was defined as a BMI $\geq 30 \mathrm{~kg} / \mathrm{m}^{2}$ and abdominal obesity if waist circumference $>94 \mathrm{~cm}$ in men and $>80 \mathrm{~cm}$ in women or waist to hip ratio $>1$ in males and $>0.85$ in females. Tobacco use was defined as history of smoking within the last 6 months.

Alcohol use was defined as history of an average alcohol consumption greater than 14 bottles of beer or equivalent a week for men and greater than 7 bottles of beer or equivalent for women week within the last 6 months [37].

Non-traditional cardiovascular risk factors were: anemia, hyperuricemia, proteinuria and a high calcium-phosphate product.

Proteinuria was defined as urinary protein excretion $>150 \mathrm{mg} / \mathrm{g}$ [15]. Hyperuricemia was defined as serum uric acid level $>70 \mathrm{mg} / \mathrm{l}$ for men and $>60 \mathrm{mg} / \mathrm{l}$ for women [38] or use of hypouricemic agents. Anemia was defined as hemoglobin of less than $13 \mathrm{~g} / \mathrm{l}$ in males and less than $12 \mathrm{~g} / \mathrm{l}$ in females [15]. Calcium phosphorus product was considered high if $\mathrm{Ca} \times \mathrm{PO}_{4}>55 \mathrm{mg}^{2} / \mathrm{dl}^{2}$.

CVD was defined as a history of stroke, peripheral artery disease, coronary heart disease (CHD), left ventricular hypertrophy (LVH), heart failure (HF) or arrhythmia.

Peripheral artery disease was defined as prior radiological confirmation of atherosclerosis of limbs vessels or absence of lower limbs pulses. Coronary heart 
disease was defined as history of myocardial infarction or ST segment abnormalities or abnormal Q waves on ECG. LVH was defined using either the Sokolow-Lyon Criteria or by the Cornell voltage criteria on ECG [35]. HF was defined as any systolic or diastolic dysfunction of the heart confirmed by a physician with or without an ejection fraction less than $50 \%$. Arrhythmia was considered as a history of atrial fibrillation with current medication or ECG signs of atrial fibrillation.

Target values were: blood pressure $<140 / 90 \mathrm{mmHg}$ for patient [39], Hemoglobin $\geq 11$ g/dl. [22], LDL cholesterol $<1$ g/l [36], Phosphorus level $<5.5 \mathrm{mg} / \mathrm{dl}$ [40].

\subsection{Statistical Analysis}

Data was analyzed with the aid of EPI Info Version 7 software. Continuous variables were presented as means (standard deviation) when distribution is symmetrical or median (25th-75th IQR) when skewed. Categorical data were expressed as frequencies, proportions and percentages. Comparison between proportions was done using chi-square test and fisher's exact where appropriate. Means were compared using the t-test for comparison of two means and ANOVA test for more than two means. The degree of association between qualitative variables was evaluated by estimating odds ratio. The level of statistical significance was set at a $\mathrm{p}$ value $<0.05$.

\section{Results}

\section{Characteristics of study population}

A total of 83 participants were included among which 45 (54.2\%) males and mean age was $56 \pm 15$ years. The median (IQR) estimated GFR was 16 (7 - 35) $\mathrm{ml} / \mathrm{min} / 1.73 \mathrm{~m}^{2}$ (Table 1$)$. Half of the participants $(\mathrm{n}=42)$ were at CKD Stage 5 , while $33.7 \%(\mathrm{n}=28)$ were at Stage 3 and $15.7 \%(\mathrm{n}=13)$ at Stage 4 and. Mean SBP and DBP were $144.8 \pm 24.1 \mathrm{mmHg}$ and $89.1 \pm 14.1 \mathrm{mmHg}$ respectively and showed a non-significant increase across CKD stages (Table 1). Hypertension (37.35\%), diabetes (20.48\%) and chronic glomerulonephritis (12.05\%) were the main causes of CKD. The etiology was undetermined in $10 \%$ of patients (Figure 1 ).

\section{Prevalence of CVRF, CVD and treatment}

The mean number of CVRF in the study population was $5.19 \pm 1.64$ (Figure 2) and the number increased although not significantly with severity of CKD (Table 2). The mean number of non-traditional CVRF significantly increased with stage of CKD $(\mathrm{p}=0.004)$. Hypertension $(90.3 \%)$, abdominal obesity (79.5\%), dyslipidemias (69.8\%), and diabetes (42.1\%) were the most frequent traditional CVRF, while anemia (78.3\%), hyperuricemia (69.8\%) and proteinuria (44.5\%) were frequent non-traditional factors. Alcohol use decreased significantly with the stages of CKD, while anemia and proteinuria increased significantly with the severity of disease (Table 2).

The mean number of CVD per patient was $1.5 \pm 0.6$ with an overall preva- 
lence of $69.8 \%(\mathrm{n}=58)$. LVH $(48.2 \%)$ and CHD (30.1\%) were the most frequent CVD found. Prevalence of CVD $(p=0.022)$, LVH $(p=0.009)$ and CHD $(p=$ 0.02 ) increased significantly with the severity of CKD (Table 2). All patients with hypertension were on antihypertensive drugs and $61 \%$ of them on RAAS blockade. Treatment of other risk factors was as followed: dyslipidemia (53.4\%), anaemia (75.3\%) hyperuricemia (72.4\%), and hypophosphatemia (81.8\%). Target values were achieved in $51.6 \%$ of participants for LDL-cholesterol, $59.1 \%$ for phosphate, $26.6 \%$ for blood pressure and $6 \%$ for haemoglobin. The control rates of dyslipidaemia decreased significantly. Please check Table 3.

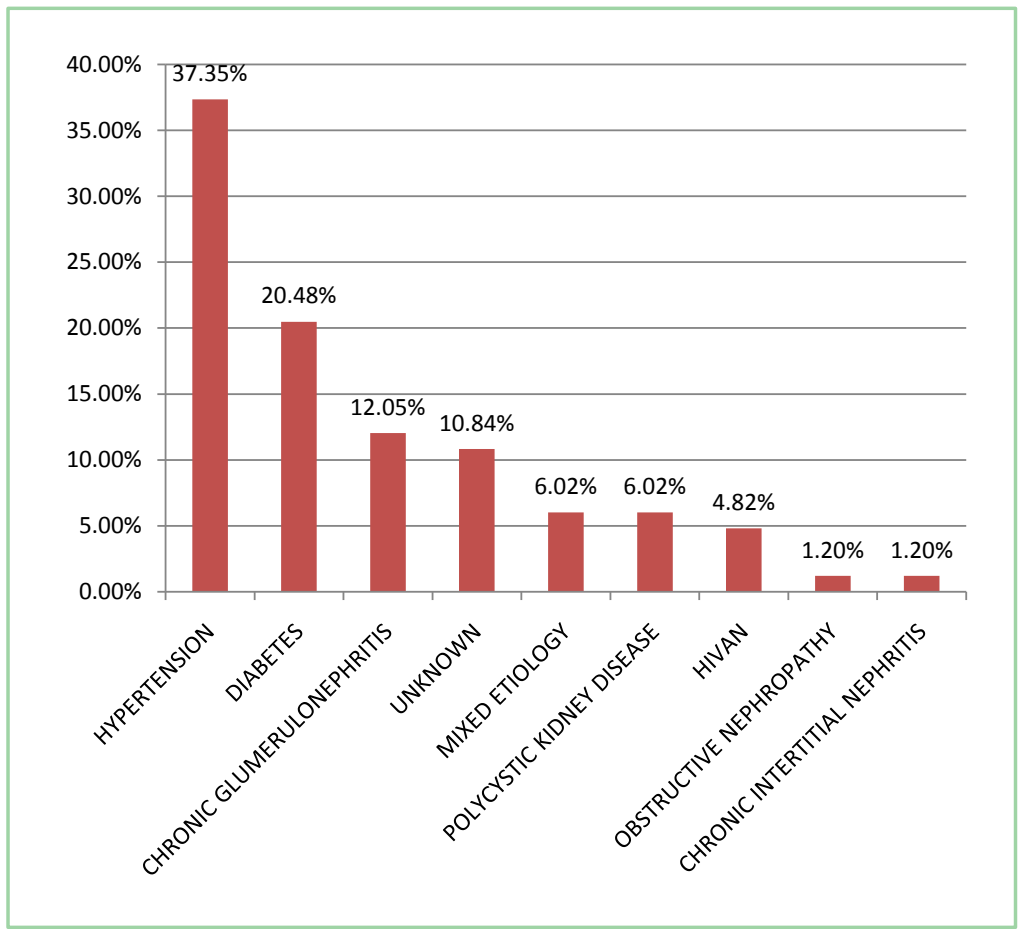

Figure 1. Possible etiologies of CKD in the study population $(n=83)$.

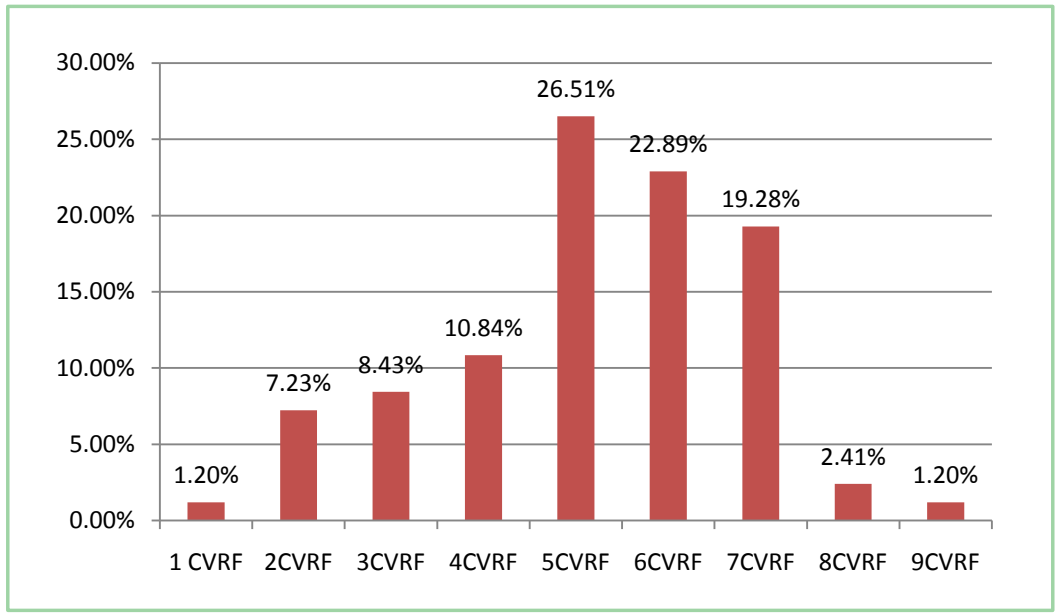

Figure 2. Distribution of participants by number of cardiovascular risk factors $(n=83)$. 
Table 1. Comparison of clinical data across the stages of CKD in our study population.

\begin{tabular}{|c|c|c|c|c|c|}
\hline Variable & $\begin{array}{c}\text { Total } \\
(\mathrm{n}=83)\end{array}$ & $\begin{array}{l}\text { Stage } 3 \\
(\mathrm{n}=28)\end{array}$ & $\begin{array}{l}\text { Stage } 4 \\
(n=13)\end{array}$ & $\begin{array}{l}\text { Stage } 5 \\
(\mathrm{n}=42)\end{array}$ & p-value \\
\hline Age (years) & $56.6 \pm 15.5$ & $59.8 \pm 14.1$ & $60.8 \pm 5.4$ & $53.2 \pm 17.8$ & 0.121 \\
\hline eGFR (ml/min) & $\begin{array}{c}16 \text { (range } 1 \text { - 59, } \\
\text { IQR } 7 \text { - 35) }\end{array}$ & $41.1 \pm 8.18$ & $21.2 \pm 4.16$ & $7.80 \pm 3.85$ & $<0.001$ \\
\hline BMI $\left(\mathrm{kg} / \mathrm{m}^{2}\right)$ & $26.4 \pm 5.01$ & $27.8 \pm 5.6$ & $26.6 \pm 5.04$ & $25.4 \pm 4.3$ & 0.134 \\
\hline $\mathrm{WC}(\mathrm{cm})$ & $90.8 \pm 12.4$ & $93.6 \pm 13.8$ & $92.2 \pm 10.1$ & $88.6 \pm 11.9$ & 0.241 \\
\hline WHR & $0.88 \pm 0.08$ & $0.87 \pm 0.07$ & $0.91 \pm 0.04$ & $0.88 \pm 0.1$ & 0.405 \\
\hline $\mathrm{SBP}(\mathrm{mmHg})$ & $144.8 \pm 24.1$ & $140.3 \pm 18.9$ & $150.4 \pm 25.5$ & $146 \pm 26.7$ & 0.419 \\
\hline DBP (mmHg) & $89.1 \pm 14.1$ & $87 \pm 14.5$ & $92.3 \pm 10.7$ & $89.6 \pm 14.8$ & 0.516 \\
\hline
\end{tabular}

eGFR = Estimated glomerular filtration rate, SBP $=$ Systolic blood pressure, $\mathrm{DBP}=$ Diastolic blood pressure; $\mathrm{BMI}=$ Body Mass index WC $=$ Waist circumference, $\mathrm{WHR}=$ Waist to hip ratio.

Table 2. Distribution of CVRF and Cardiovascular Diseases according to CKD stages.

\begin{tabular}{|c|c|c|c|c|c|}
\hline \multicolumn{6}{|c|}{ Traditional risk factors $\mathrm{n}(\%)$} \\
\hline Variable & $\begin{array}{c}\text { Total } \\
(\mathrm{n}=83)\end{array}$ & $\begin{array}{l}\text { Stage } 3 \\
(\mathrm{n}=28)\end{array}$ & $\begin{array}{l}\text { Stage } 4 \\
(\mathrm{n}=13)\end{array}$ & $\begin{array}{c}\text { Stage } 5 \\
(\mathrm{n}=42)\end{array}$ & $P$ value \\
\hline $\mathrm{CVRF}^{*}$ & $3.24 \pm 1.24$ & $3.29 \pm 1.53$ & $3.15 \pm 0.89$ & $3.23 \pm 1.14$ & 0.94 \\
\hline Hypertension & $75(90.36 \%)$ & $25(33.33 \%)$ & $12(16.00 \%)$ & $38(50.67 \%)$ & 0.95 \\
\hline Abdominal obesity & $66(79.52 \%)$ & $21(31.82 \%)$ & $11(16.67 \%)$ & $34(51.52 \%)$ & 0.73 \\
\hline Dyslipidemia & $58(69.88 \%)$ & $16(27.59 \%)$ & $8(13.79 \%)$ & $34(58.62 \%)$ & 0.08 \\
\hline Diabetes & $35(42.17 \%)$ & $11(31.43 \%)$ & $7(20.00 \%)$ & $17(48.57 \%)$ & 0.64 \\
\hline Obesity & $19(22.8 \%)$ & $10(52.63 \%)$ & $3(15.79 \%)$ & $6(31.58 \%)$ & 0.09 \\
\hline Alcohol use & $12(14.46 \%)$ & $8(66.67 \%)$ & $0(0.00 \%)$ & $4(33.33 \%)$ & 0.02 \\
\hline Tobacco use & $3(3.61 \%)$ & $0(0.00 \%)$ & $1(33.33 \%)$ & $2(66.67 \%)$ & 0.40 \\
\hline \multicolumn{6}{|c|}{ Nontraditional risk factors $\mathrm{n}(\%)$} \\
\hline CVRF* $^{*}$ & $1.96 \pm 0.78$ & $1.64 \pm 0.62$ & $1.76 \pm 1.09$ & $2.23 \pm 0.69$ & 0.004 \\
\hline Anemia & $65(78.31)$ & $19(29.23 \%)$ & $8(13.32 \%)$ & $38(56.46 \%)$ & 0.02 \\
\hline Hyperuricemia & $58(69.88 \%)$ & $21(36.21 \%)$ & $8(13.79 \%)$ & $29(50.00 \%)$ & 0.67 \\
\hline Proteinuria & $37(44.58 \%)$ & $7(18.82 \%)$ & $5(13.51 \%)$ & $25(67.57 \%)$ & 0.015 \\
\hline $\mathrm{Ca} \times \mathrm{P}$ & $4(4.88)$ & $0(0.00 \%)$ & $1(25 \%)$ & $3(75 \%)$ & 0.33 \\
\hline \multicolumn{6}{|c|}{ Cardiovascular disease $\mathrm{n}(\%)$} \\
\hline CVD Total & $58(69.8 \%)$ & $15(25.8 \%)$ & $8(13.8 \%)$ & $35(60.3 \%)$ & 0.02 \\
\hline LVH & $40(48.2 \%)$ & $7(17.5 \%)$ & $7(17.5 \%)$ & $26(65.0 \%)$ & 0.009 \\
\hline $\mathrm{CHD}$ & $25(30.1 \%)$ & $8(32 \%)$ & $0(0.0 \%)$ & $17(68 \%)$ & 0.02 \\
\hline $\mathrm{HF}$ & $10(12 \%)$ & $4(40 \%)$ & $0(0.0 \%)$ & $6(60 \%)$ & 0.34 \\
\hline Stroke & $6(7.2 \%)$ & $2(33.3 \%)$ & $2(33.3 \%)$ & $2(33.3 \%)$ & 0.43 \\
\hline PAD & $4(4.8 \%)$ & $2(50 \%)$ & $2(50 \%)$ & $0(0.0 \%)$ & 0.06 \\
\hline $\mathrm{AF}$ & $2(2.4 \%)$ & $0(0.0 \%)$ & $0(0.0 \%)$ & $2(100 \%)$ & 0.36 \\
\hline
\end{tabular}

$\mathrm{CVRF}^{*}=$ Mean number of CVRF, $\mathrm{Ca} \times \mathrm{P}=$ Calcium Phosphorus product CVD $=$ Cardiovascular Disease, $\mathrm{LVH}=$ Left ventricular Hypertrophy $\mathrm{CHD}=$ Coronary Heart Disease, HF $=$ Heart Failure, PAD $=$ Peripheral Artery Disease, AF = Atrial Fibrillation. 
Table 3. Management and control rates of some CVRF across the stages of CKD.

\begin{tabular}{|c|c|c|c|c|c|c|}
\hline $\begin{array}{c}\text { Control CVRF } \\
\text { CVRF }\end{array}$ & $\begin{array}{l}\text { Stage } 3 \\
\mathrm{~N}(\%)\end{array}$ & $\begin{array}{l}\text { Stage } 4 \\
\mathrm{~N}(\%)\end{array}$ & $\begin{array}{l}\text { Stage } 5 \\
\mathrm{~N}(\%)\end{array}$ & $P$ value & $\begin{array}{l}\text { Total } \\
\mathrm{N}(\%)\end{array}$ & \\
\hline \multirow[t]{3}{*}{$\begin{array}{l}\text { Hypertension } \\
\qquad(\mathrm{n}=75)\end{array}$} & $\begin{array}{c}\text { Anti-hypertensive } \\
\text { use }\end{array}$ & $25(33.3 \%)$ & $12(16 \%)$ & $38(50.6 \%)$ & 0.95 & $75(100 \%)$ \\
\hline & $\begin{array}{c}\% \text { on RAAS } \\
\text { blockers }\end{array}$ & $17(36.9 \%)$ & $7(15.2 \%)$ & $22(47.8 \%)$ & 0.70 & $46(61.3 \%)$ \\
\hline & Optimal control & $6(30 \%)$ & $1(5 \%)$ & $13(65 \%)$ & 0.19 & $20(26.6 \%)$ \\
\hline \multirow[t]{2}{*}{$\begin{array}{l}\text { Dyslipidemia } \\
\quad(\mathrm{n}=58)\end{array}$} & Statin use n (\%) & $10(32.3 \%)$ & $4(12.9 \%)$ & $17(54.8 \%)$ & 0.79 & $31(53.4 \%)$ \\
\hline & Optimal control & $9(56.2 \%)$ & $1(6.2 \%)$ & $6(37.5 \%)$ & 0.01 & $16(51.6 \%)$ \\
\hline \multirow[t]{2}{*}{$\begin{array}{l}\text { Hyperphosphatemia } \\
\qquad(\mathrm{n}=11)\end{array}$} & $\begin{array}{l}\text { phosphate } \\
\text { binders use }\end{array}$ & $0(0.0 \%)$ & $2(22.2 \%)$ & $7(77.7 \%)$ & - & $9(81.8 \%)$ \\
\hline & Optimal control & $1(7.7 \%)$ & $0(0.0 \%)$ & $12(92.3 \%)$ & 0.15 & $13(59.1 \%)$ \\
\hline \multirow[t]{2}{*}{$\begin{array}{l}\text { Anemia } \\
(n=65)\end{array}$} & $\%$ on treatment & $9(18.3 \%)$ & $8(16.3 \%)$ & $32(65.3 \%)$ & 0.12 & $49(75.3 \%)$ \\
\hline & Optimal control & $1(33.3 \%)$ & $0(0.0 \%)$ & $2(66.6 \%)$ & 0.67 & $3(6.0 \%)$ \\
\hline $\begin{array}{l}\text { Hyperuricemia } \\
\qquad(\mathrm{n}=58)\end{array}$ & $\%$ on treatment & $14(33.3 \%)$ & $6(14.29 \%)$ & $22(52.3 \%)$ & 0.92 & $42(72.4 \%)$ \\
\hline $\begin{array}{l}\text { Proteinuria } \\
\quad(\mathrm{n}=37)\end{array}$ & $\begin{array}{c}\% \text { on RAAS } \\
\text { blockers }\end{array}$ & $6(25 \%)$ & $3(12.5 \%)$ & $15(62.5 \%)$ & 0.088 & $24(64.8 \%)$ \\
\hline
\end{tabular}

\section{Discussion}

In the present study including 83 patients with CKD stage 3 - 5 ND in Cameroon, we found that CVD more than $2 / 3$ of participants presented at least one CVD with LVH, CHD and HF being the most frequent. Prevalence of CVD, LVH and CHD increased with the severity of CKD. The mean number of CVRF was $5.19 \pm 1.64$. Hypertension (90.3\%), abdominal obesity (79.5\%), anemia (78.3\%), hyperuricemia (69.8\%), dyslipidemia (69.8\%), proteinuria (44.5\%) and diabetes $(42.1 \%)$ were the most frequent CVRF. The management of these factors was appropriate for the majority but control was poor especially for blood pressure and anaemia.

\section{Prevalence CVRF}

We found a mean number of 5 CVRF per patient with traditional CVRF accounted for over two-thirds of the risk burden. When only traditional factors were considered, there was a mean number of 3 traditional CVRF higher than the 1 - 2 factors reported in some high-income countries [41] [42]. Early presentation of patients for medical care, universal access to healthcare and less physicians' inertia towards therapeutic guidelines may account for the lower numbers in those countries [41] [42] [43]. Hypertension was the most common CVRF and constitutes the leading cause of CKD in Sub-Saharan Africa [26] [30] [31] as well as complication [44]; this could explain the higher prevalence of coronary artery disease (CAD) and LVH is these patients with CKD as noted elsewhere ranging from $87 \%$ to $90 \%$ [6]. Obesity was present in $23.17 \%$ of pa- 
tients higher than the mean urban prevalence reported in Cameroon [45]; this may reflect the rising epidemic of obesity observed in Africa and worldwide [46] also obesity is the main risk factor for hypertension and diabetes the 2 leading cause of CKD in our setting [29]. Few studies have reported on the prevalence of obesity in the CKD population, with rates varying from $16 \%$ - 38\% depending on the method of diagnosis and the definition [28] [42] [47] with the severity of CKD. We found anaemia, hyperuricemia and proteinuria as common non-traditional CVRF in this CKD population. Few studies include non-traditional CVRF in computing the number of factors in CKD [48]. As expected, anaemia and proteinuria increased with the severity of CKD. The prevalence of hyperuricemia was high with about half of these patients at CKD. Similarly, Chonchol et al. reported an increase in the prevalence of hyperuricemia with GFR decline [49]. The prevalence of proteinuria in CKD varies worldwide due to the definition, and clinical characteristics of the study population. The prevalence of proteinuria in the present study was $44,5 \%$. This is higher compared to most studies in the literature that range from $3 \%-37 \%$ [50], but lower to the prevalence found by in other studies in Africa [28] [47].

\section{Prevalence of CVD}

More than $2 / 3$ of participants presented at least one CVD and the rates increased significantly with the severity of CKD; this is in consonance with the findings in literature [2] [8] [10]. CVD is the leading cause of morbidity and mortality [11] in CKD patients with reported prevalence ranging from $26 \%$ to 48\% [4] [5] [6] [7]. LVH and CHD were the most common CVD similar to other studies in SSA [50] [51]. The high prevalence of hypertension, anaemia and patients with advanced CKD in our study may explain this high prevalence. About $12 \%$ of the population had heart failure with $2 / 3$ of individuals in CKD stage 5. Much higher rates were reported in the western world [52]. The difference is due to diagnostic criteria. Our prevalence of CHD (30\%) was higher than reported in patients on haemodialysis in Cameroon [53], which may suggest that majority of patients with CHD die before getting to end stage renal disease. Also our diagnosis of CHD was mostly made by ST segment changes on ECG, which is not specific to ischemia, and could increase the prevalence.

\section{Management}

We found that $2 / 3$ of patients with proteinuria and $61 \%$ with hypertension were on RAAS blockers. Our rate of RAAS blockers use was much lower compared to other studies in similar population in Cameroon [28] [54]. This could be due to the fact that the majority of our participants were in advanced stage of CKD where the use of RAAS blockers can be harmful [55]. Control of hypertension in CKD is difficult [4] [26]. Only $26 \%$ of our population achieved their BP target value. Other studies in Cameroon have reported low control rates [28] [54]. The change in the target value as suggested by the JNC 8 made target values in CKD more permissive.

It is fundamental in managing $\mathrm{CV}$ complication in CKD to target dyslipide- 
mia [19]. About half of participants with dyslipidaemia were on statins. Higher rates were shown in a population in Taiwan [39]. This low rate of statin use in our study could be due to the high cost of the drug that is out of pocket payment in our setting [56]. The control of LDL-cholesterol was optimal in half of the patients on statin and the rate decreased significantly with the severity of CKD. Higher control rate were reported by Akpan et al. and Lin et al. in Taiwan amongst CKD patients stages 1 - $5 \mathrm{ND}$ [27] [55]. We found that just $6 \%$ of patients met their target haemoglobin. This was in conformity with the findings of Nicola et al. [43] in Italy. The control rates of anaemia a risk factor of LVH is poor and one main reason is the high cost of erythropoietin stimulating agent that is out of pocket payment in our setting [20]. We observed $72 \%$ of patients with hyperuricemia were on a hypouricemic agent. They are no guidelines that suggest we should treat asymptomatic hyperuricemia. However, studies have shown that hyperuricemia is a factor of progression of CKD and that treatment reduces this progression [57].

\section{Strength and Limitations}

This study has some limitations: We use ECG criteria to determine LVH and did not confirm with echocardiography. Also blood pressure control was defined using office values and ambulatory blood pressure monitoring would have been a preferred means. We used self-report and review of medical records to define CVD in this study. This may have missed a small group of participants with undiagnosed CVD. This was a single center study and the results could not be generalized. Despite these limitations, this is the first study to provide basic information on the burden of CVRF and CVD in CKD patients in our setting.

\section{Conclusion}

In conclusion, this study reported that CKD patients have a high prevalence of CVD and CVRF. Adequate control risk of these factors is important to reduce mortality of patients but controls were suboptimal in our setting especially for hypertension and anemia. This basic evaluation may serve as foundation for further studies with a big sample and follow up data.

\section{Acknowledgements}

We want to thank the staff of the nephrology and cardiology unit of the Douala General Hospital and all the patients who participated in the study.

\section{Ethics Approval and Consent to Participate}

This study received administrative authorization from the Douala general hospital. Ethical clearance was obtained from the institutional ethics committee for research on human health of the University of Douala No IEC-UD/505/02/2016/T. All participants provided a written informed consent before enrolment. 


\section{Consent for Publication}

All authors gave their approval for publication.

\section{Funding}

The authors did not receive any funds for this study.

\section{Authors' Contribution Statement}

Study conception-HMP, AEG

Clinical data collection and supervision-KMF, KF, HMP, FH, AEG

Acquisition and validation of the biological data-KMF, KF, HMP, AEG

Data analysis-KMF

Data interpretation-KMF, HMP, DA, MS, KFF, AEG

Manuscript drafting-KMF, HMP

Critical revision of the manuscript-KF, HMP, DA, MS, KFF, AEG

\section{Availability of Data and Materials}

Data and materials are available with corresponding author which is the principal investigator. They can be consulted at any time upon request. However, the ethical clearance and the inform consent form did mention that patient data could be shared to a third party.

\section{Conflicts of Interest}

The authors declare no conflicts of interest regarding the publication of this paper.

\section{References}

[1] Hill, N.R., Fatoba, S.T., Oke, J.L., Hirst, J.A., O’Callaghan, C.A., Lasserson, D.S., et al. (2016) Global Prevalence of Chronic Kidney Disease-A Systematic Review and Meta-Analysis. PLoS ONE, 11, e0158765. https://doi.org/10.1371/journal.pone.0158765

[2] Kazancioglu, R. (2013) Risk Factors for Chronic Kidney Disease: An Update. Kidney International Supplements, 3, 368-371. https://doi.org/10.1038/kisup.2013.79

[3] Vanholder, R., Massy, Z., Argiles, A., Spasovski, G., Verbeke, F. and Lameire, N. (2005) Chronic Kidney Disease as Cause of Cardiovascular Morbidity and Mortality. Nephrology Dialysis Transplantation, 20, 1048-1056. https://doi.org/10.1093/ndt/gfh813

[4] Sarnak, M.J. and Levey, A.S. (2000) Epidemiology, Diagnosis, and Management of Cardiac Disease in Chronic Renal Disease. Journal of Thrombosis and Thrombolysis, 10, 169-180. https://doi.org/10.1023/A:1018718727634

[5] Baigent, C., Burbury, K. and Wheeler, D. (2000) Premature Cardiovascular Disease in Chronic Renal Failure. The Lancet, 365, 147-152. https://doi.org/10.1016/S0140-6736(00)02456-9

[6] Levin, A., Djurdjev, O. and Barrett, B. (1999) Burgess Cardiovascular Disease and 
Mortality in a Community-Based Cohort with Mild Renal Insufficiency. Kidney International, 56, 2214-2219. https://doi.org/10.1046/j.1523-1755.1999.00773.x

[7] Carlisle, E., Ethier, J., Jindal, K., Mendelssohn, D., Tobe, S., Singer, J. and Thompson, C. (2001) Cardiovascular Disease in Patients with Chronic Kidney Disease: Getting to the Heart of the Matter. American Journal of Kidney Diseases, 38, 1398-1407. https://doi.org/10.1053/ajkd.2001.29275

[8] Stevens, L.A., Li, S., Wang, C., Huang, C., Becker, B.N., Bomback, A.S., Brown, W.W., Burrows, N.R., Jurkovitz, C.T., McFarlane, S.I., Norris, K.C., Shlipak, M., Whaley-Connell, A.T., Chen, S.C., Bakris, G.L. and McCullough, P.A. (2010) Prevalence of CKD and Comorbid Illness in Elderly Patients in the United States: Results from the Kidney Early Evaluation Program (KEEP). American Journal of Kidney Diseases, 55, S23-S33. https://doi.org/10.1053/j.ajkd.2009.09.035

[9] Anavekar, N.S., McMurray, J.J.V., Velazquez, E.J., et al. (2004) Relation between Renal Dysfunction and Cardiovascular Outcomes after Myocardial Infarction. The New England Journal of Medicine, 351, 1285-1295.

[10] Go, A.S., Chertow, G.M., Fan, D., et al. (2004) Chronic Kidney Disease and the Risks of Death, Cardiovascular Events, and Hospitalization. The New England Journal of Medicine, 351, 1296-1305. https://doi.org/10.1056/NEJMoa041031

[11] Shastri, S. and Sarnak, M.J. (2010) Cardiovascular Disease and CKD: Core Curriculum 2010. American Journal of Kidney Diseases, 56, 399-417.

https://doi.org/10.1053/j.ajkd.2010.03.019

[12] Levin, A. (2003) Clinical Epidemiology of Cardiovascular Disease in Chronic Kidney Disease Prior to Dialysis. Seminars in Dialysis, 16, 101-105. https://doi.org/10.1046/j.1525-139X.2003.16025.x

[13] Ritchie, J., Rainone, F., Green, D., et al. (2013) Extreme Elevations in Blood Pressure and All-Cause Mortality in a Referred CKD Population: Results from the Crisis Study. International Journal of Hypertension, 2013, Article ID: 597906. https://doi.org/10.1155/2013/597906

[14] Martinez-Castelao, A., Gorriz, J.L., Portoles, J.M., et al. (2011) Baseline Characteristics of Patients with Chronic Kidney Disease Stage 3 and Stage 4 in Spain: The MERENA Observational Cohort Study. BMC Nephrology, 12, 53. https://doi.org/10.1186/1471-2369-12-53

[15] Kidney Disease: Improving Global Outcomes (KDIGO) CKD Work Group (2013) KDIGO 2012 Clinical Practice Guideline for the Evaluation and Management of Chronic Kidney Disease. Kidney International, 3, 1-150.

[16] Zannad, F., Kessler, M., Lehert, P., Grunfeld, J.P., Thuilliez, C., Leizorovicz, A. and Lechat, P. (2006) Prevention of Cardiovascular Events in End-Stage Renal Disease: Results of a Randomized Trial of Fosinopril and Implications for Future Studies. Kidney International, 70, 1317-1324. https://doi.org/10.1038/sj.ki.5001657

[17] Berl, T., Hunsicker, L.G., Lewis, J.B., Pfeffer, M.A., Porush, J.G., Rouleau, J.L., Drury, P.L., Esmatjes, E., Hricik, D., Parikh, C.R., Raz, I., Vanhille, P., Wiegmann, T.B., Wolfe, B.M., Locatelli, F., Goldhaber, S.Z., Lewis, E.J., Irbesartan Diabetic Nephropathy Trial. Collaborative Study Group (2003) Cardiovascular Outcomes in the Irbesartan Diabetic Nephropathy Trial of Patients with Type 2 Diabetes and Overt Nephropathy. Annals of Internal Medicine, 138, 542-549.

[18] Kidney Disease Outcomes Quality Initiatives (K/DOQI) (2007) Clinical Practice Guidelines and Clinical Practice Recommendations for Diabetes and Chronic Kidney Disease. American Journal of Kidney Diseases, 49, S12-S154.

https://doi.org/10.1053/j.ajkd.2006.12.005 
[19] Shepherd, J., Kastelein, J.J., Bittner, V., Deedwania, P., Breazna, A., Dobson, S., Wilson, D.J., Zuckerman, A., Wenger, N.K., TNT (Treating to New Targets) Investigators (2008) Intensive Lipid Lowering with Atorvastatin in Patients with Coronary Heart Disease and Chronic Kidney Disease: The TNT (Treating to New Targets) Study. Journal of the American College of Cardiology, 51, 1448-1454. https://doi.org/10.1016/j.jacc.2007.11.072

[20] Parfrey, P.S., Lauve, M., Latremouille-Viau, D. and Lefebvre, P. (2009) Erythropoietin Therapy and Left Ventricular Mass Index in CKD and ESRD Patients: A Meta-Analysis. Clinical Journal of the American Society of Nephrology, 4, 755-762. https://doi.org/10.2215/CJN.02730608

[21] Di Lullo, L., Floccari, F., Granata, A. and Malaguti, M. (2012) Low-Dose Treatment with Erythropoiesis-Stimulating Agents and Cardiovascular Geometry in Chronic Kidney Disease: Is Darbepoetin- $\alpha$ More Effective than Expected? Cardiorenal Medicine, 2, 18-25. https://doi.org/10.1159/000334942

[22] Kidney Disease Outcomes Quality Initiatives (K/DOQI) (2007) Clinical Practice Guidelines and Clinical Practice Recommendations for Anemia in Chronic Kidney Disease. American Journal of Kidney Diseases, 49, S12-S154. https://doi.org/10.1053/j.ajkd.2006.12.005

[23] Kidney Disease Outcomes Quality Initiatives (K/DOQI) (2009) Clinical Practice Guideline for the Diagnosis, Evaluation, Prevention and Treatment of Chronic Kidney Disease-Mineral and Bone Disorder (CKD-MBD). Treatment of CKD-MBD Targeted at Lowering High Serum Phosphorus and Maintaining Serum Calcium. Kidney International, 76, S50. https://doi.org/10.1038/ki.2009.192

[24] Di Lullo, L., Floccari, F., Santoboni, A., Barbera, V., Rivera, R.F., Granata, A., Morrone, L. and Russo, D. (2013) Progression of Cardiac Valve Calcification and Decline of Renal Function in CKD Patients. Journal of Nephrology, 26, 739-744. https://doi.org/10.5301/jn.5000290

[25] Collins, A.J., Foley, R.N., Herzog, C., et al. (2010) Excerpts from the US Renal Data System 2009 Annual Data Report. American Journal of Kidney Diseases, 55, S1-A7. https://doi.org/10.1053/j.ajkd.2009.10.009

[26] Stanifer, J.W., Jing, B., Tolan, S., Helmke, N., Mukerjee, R., Naicker, S. and Patel, U. (2014) The Epidemiology of Chronic Kidney Disease in Sub-Saharan Africa: A Systematic Review and Meta-Analysis. The Lancet Global Health, 2, 174-181. https://doi.org/10.1016/S2214-109X(14)70002-6

[27] Akpan, E.E., Ekrikpo, U.E., Effa, E.E., Udo, A.I.A. and Kadiri, S. (2014) Assessment of Dyslipidemia in Pre-Dialysis Patients in South-West Nigeria. Nigerian Medical Journal, 55, 214-219. https://doi.org/10.4103/0300-1652.132043

[28] Tene, U. (2011) The Epidemiologic Profile of Cardiac Diseases in Patients with Non Dialysis Dependent Chronic Kidney Disease [Thesis]. Fac. Med Biomed Sci., Yaounde.

[29] Kaze, F.F., Kengne, A.-P., Magatsing, C.T., Halle, M.-P., Yiagnigni, E. and Ngu, K.B. (2016) Prevalence and Determinants of Chronic Kidney Disease among Hypertensive Cameroonians According to Three Common Estimators of the Glomerular Filtration Rate. Journal of Clinical Hypertension, 18, 408-414. https://doi.org/10.1111/jch.12781

[30] Kaze, F.F., Halle, M.-P., Mopa, H.T., Ashuntantang, G., Fouda, H., Ngogang, J., et al. (2015) Prevalence and Risk Factors of Chronic Kidney Disease in Urban Adult Cameroonians According to Three Common Estimators of the Glomerular Filtration Rate: A Cross-Sectional Study. BMC Nephrology, 16, Article No. 96. 
https://doi.org/10.1186/s12882-015-0102-9

[31] Halle, M.P., Takongue, C., Kengne, A.P., Kaze, F.F. and Ngu, K.B. (2015) Epidemiological Profile of Patients with End Stage Renal Disease in a Referral Hospital in Cameroon. BMC Nephrology, 16, Article No. 59.

https://doi.org/10.1186/s12882-015-0044-2

[32] Halle, M.P., Ashuntantang, G., Kaze, F.F., Takongue, C. and Kengne, A.-P. (2016) Fatal Outcomes among Patients on Maintenance Haemodialysis in Sub-Saharan Africa: A 10-Year Audit from the Douala General Hospital in Cameroon. BMC Nephrology, 17, Article No. 165. https://doi.org/10.1186/s12882-016-0377-5

[33] Halle, M.P.E., Kengne, A.P. and Ashuntantang, G. (2009) Referral of Patients with Kidney Impairment for Specialist Care in a Developing Country of Sub-Saharan Africa. Renal Failure, 31, 341-348. https://doi.org/10.1080/08860220902882014

[34] Levey, A.S. and Stevens, L.A. (2010) Estimating GFR Using the CKD Epidemiology Collaboration (CKD-EPI) Creatinine Equation: More Accurate GFR Estimates, Lower CKD Prevalence Estimates, and Better Risk Predictions. American Journal of Kidney Diseases, 55, 622-627. https://doi.org/10.1053/j.ajkd.2010.02.337

[35] Kligfield, et al. (2007) Standardization and Interpretation of the ECG, Part I. Circulation, 115, 1306-1324. https://doi.org/10.1161/CIRCULATIONAHA.106.180200

[36] Kidney Disease Outcomes Quality Initiative (K/DOQI) Group (2003) K/DOQI Clinical Practice Guidelines for Managing Dyslipidemias in Chronic Kidney Disease. American Journal of Kidney Diseases, 41, S1-S91.

[37] Whitman, I.R., Agarwal, V., Nah, G., et al. (2017) Alcohol Abuse and Cardiac Disease. Journal of the American College of Cardiology, 69, 13-24. https://doi.org/10.1016/j.jacc.2016.10.048

[38] Chuang, S.Y., Chen, J.H., Yeh, W.T., Wu, C.C. and Pan, W.H. (2012) Hyperuricemia and Increased Risk of Ischemic Heart Disease in a Large Chinese Cohort. International Journal of Cardiology, 154, 316-321.

[39] Armstrong, C. and Joint National Committee (2014) JNC 8 Guidelines for the Management of Hypertension in Adults. American Family Physician, 90, 503-504.

[40] KDIGO (2009) KDIGO Clinical Practice Guideline for the Diagnosis, Evaluation, Prevention, and Treatment of Chronic Kidney Disease-Mineral Bone Disorder (CKD-MBD). Kidney International Supplements, 76, S1-S130.

[41] Sagun, G., Kantarci, G., Mesci, B., Gungor, S., Turkoglu, F., Yorulmaz, E., et al. (2010) Frequency of Cardiovascular Risk Factors and Metabolic Syndrome in Patients with Chronic Kidney Disease. Clinical Medicine \& Research, 8, 135-141. https://doi.org/10.3121/cmr.2010.892

[42] Foster, M.C., Rawlings, A.M., Marrett, E., Neff, D., Willis, K., Inker, L.A., et al. (2013) Cardiovascular Risk Factor Burden, Treatment, and Control among Adults with Chronic Kidney Disease in the United States. American Heart Journal, 166, 150-156. https://doi.org/10.1016/j.ahj.2013.03.016

[43] De Nicola, L., Minutolo, R., Chiodini, P., Zoccali, C., Castellino, P., Donadio, C., et al. (2006) Global Approach to Cardiovascular Risk in Chronic Kidney Disease: Reality and Opportunities for Intervention. Kidney International, 69, 538-545. https://doi.org/10.1038/sj.ki.5000085

[44] Morgado, E. and Neves, P.L. (2012) Hypertension and Chronic Kidney Disease: Cause and Consequence-Therapeutic Considerations. In: Babeai, H., Ed., Antihypertensive Drugs, IntechOpen, London, 45-57. https://doi.org/10.5772/36916

[45] Kamadjeu, R.M., Edwards, R., Atanga, J.S., Kiawi, E.C., Unwin, N. and Mbanya, J.C. 
(2006) Anthropometry Measures and Prevalence of Obesity in the Urban Adult Population of Cameroon: An Update from the Cameroon Burden of Diabetes Baseline Survey. BMC Public Health, 6, Article No. 228. https://doi.org/10.1186/1471-2458-6-228

[46] Maliha, A. and Riaz, A. (2017) The Rising Prevalence of Obesity; Part A: Impact on Public Health. International Journal of Surgical Oncology, 2, e17. https://doi.org/10.1097/IJ9.0000000000000017

[47] Babua, C., Kalyesubula, R., Okello, E., Kakande, B., Sebatta, E., Mungoma, M. and Mondo, C. (2015) Pattern and Presentation of Cardiac Diseases among Patients with Chronic Kidney Disease Attending a National Referral Hospital in Uganda: A Cross Sectional Study. BMC Nephrology, 16, 126. https://doi.org/10.1186/s12882-015-0128-Z

[48] Major, R.W., et al. (2018) Cardiovascular Disease Risk Factors in Chronic Kidney Disease: A Systematic Review and Meta-Analysis PLOS ONE, 13, e0192895. https://doi.org/10.1371/journal.pone.0192895

[49] Chonchol, M., Shlipak, M.G., Katz, R., Sarnak, M.J., Newman, A.B., Siscovick, D.S., et al. (2007) Relationship of Uric Acid with Progression of Kidney Disease. American Journal of Kidney Diseases, 50, 239-247. https://doi.org/10.1053/j.ajkd.2007.05.013

[50] Amoako, Y.A. and Laryea, D.O. (2017) Left Ventricular Hypertrophy among Chronic Kidney Disease Patients in Ghana. The Pan African Medical Journal, 28, 79. https://doi.org/10.11604/pamj.2017.28.79.9183

[51] Chijioke, A., Makusidi, A.M. and Kolo, P.M. (2012) Electrocardiographic Abnormalities among Dialysis Naïve Chronic Kidney Disease Patients in Ilorin Nigeria. Annals of African Medicine, 11, 21-26. https://doi.org/10.4103/1596-3519.91011

[52] Eckardt, K.U., Scherhag, A., Macdoigall, I.C., et al. (2009) Left Ventricular Geometry Predicts Cardiovascular Outcomes Associated with Anemia Correction in CKD. Journal of the American Society of Nephrology, 20, 2651-2660. https://doi.org/10.1681/ASN.2009060631

[53] Kaze, F.F., Kengne, A.P., Ashuntantang, G., Halle, M.P., Menanga, A.P., Kingue, S., et al. (2014) Pattern and Correlates of Cardiac Lesions in a Group of Sub-Saharan African Patients on Maintenance Hemodialysis. The Pan African Medical Journal, 17, 3. https://doi.org/10.11604/pamj.2014.17.3.3422

[54] Kaze-Folefack, F., Nono, A., Halle, M.P. and Ashuntantang, G. (2015) Severity and Control of Hypertension during Chronic Kidney Disease in Cameroon. Pan African Medical Journal, 21, 205.

[55] Lin, T.-H., Chuang, S.-Y., Chu, C.-Y., Lee, W.-H., Hsu, P.-C., Su, H.-M., et al. (2014) The Impact of Chronic Kidney Disease on Lipid Management and Goal Attainment in Patients with Atherosclerosis Diseases in Taiwan. International Journal of Medical Sciences, 11, 381-388. https://doi.org/10.7150/ijms.7069

[56] Dzudie, A., Epie, N., Abanda, M., Abanda, M., Aminde, L., Hamadou, B., Dzekem, B., et al. (2020) Availability, Cost and Affordability of Essential Cardiovascular Disease Medicines in the South West Region of Cameroon: Preliminary Findings from the Cameroon Science for Disease Study. PLoS ONE, 15, e0229307. https://doi.org/10.1371/journal.pone.0229307

[57] Goicoechea, M., de Vinuesa, S.G., Verdalles, U., Ruiz-Caro, C., Ampuero, J., Rincon, A., et al. (2010) Effect of Allopurinol in Chronic Kidney Disease Progression and Cardiovascular Risk. Clinical Journal of the American Society of Nephrology, 5, 1388-1393. https://doi.org/10.2215/CJN.01580210 


\section{List of Abbreviations}

AF-Atrial Fibrillation; BMI-Body Mass Index; CKD-Chronic Kidney Disease; CaxP-Calcium Phosphorus product; CHD—Coronary Heart Disease; CVD-Cardiovascular Disease; DBP-Diastolic Blood Pressure; GFR-Glomerular Filtration Rate; HF-Heart Failure; KDIGO-Kidney Disease: Improving Global Outcomes; LVH—Left Ventricular Hypertrophy; PAD-Peripheral Artery Disease; SBP-Systolic Blood Pressure; WC-Waist Circumference; WHR-Waist to Hip Ratio 